\title{
119. The Control of Growth and Development in Bombyx mori. XXXIII
}

\author{
Electron-Microscopic Studies on the Activity of Corpus \\ Allatum in the Fifth Instar Larvae Developed from \\ Low and High Temperature Eggs
}

\author{
By Seijiro Morohoshi,*) Tadasu MorI,**) and Shigeru SATo***) \\ (Communicated by Sajiro Makino, M. J. A., Oct. 12, 1976)
}

It has been demonstrated in one of our previous reports (XXII) that the activity of corpus allatum (CA) of the 5th-instar-larvae developed from eggs incubated at low temperature is weaker than that of those incubated at high temperature. This paper deals with an electron-microscopic demonstration of the above features.

Materials and methods. Eggs of hybrids from J. $106 \mathrm{X}$ Daizo were incubated at two different temperature series: $17^{\circ} \mathrm{C}$ (L-series) and $25^{\circ} \mathrm{C}$ (H-series). The CA of the 4 th-or 5th-instar-female larvae in the both series provided materials for this study. The fixing and staining techniques for electron-microscopic observations followed Akai's method (1971).

Results and discussion. Cells of the CA of newly ecdysed 4thinstar-larvae (H-series) were found closely associated with each other. Many sack-like membrane systems occurred between those cells (Fig. 1, arrows and Fig. 9, A). The cytoplasm of the CA with a higher activity at this stage was provided with a number of Golgi apparatus, but there were no dense lysosomes. The CA cells of newly ecdysed 5th-instar-larvae (H-series) were marked by their loose association and there occurred no sack-like membrane system in them. At this stage the cells showed no Golgi apparatus while many dense lysosomes made their appearance (Fig. 2 and Fig. 9, B). The CA cells of newly ecdysed 5th-instar-larvae (L-series) showed a loose association. Following histolytic reaction of cells, cell-degeneration occurred (Fig. 3 and Fig. 9, C). Many finger-like cytoplasmic protrusions were apparent in the degenerating cells (Fig.4). The CA cytoplasm at this stage was not remarkable the distribution of Golgi apparatus and dense lysosomes, whereas the degenerating cells showed dense lysosomes.

*) Faculty of Agriculture, Tokyo University of Agriculture and Technology, Fuchu-shi, Tokyo 183, Japan.

**) Tokyo Metropolitan Horticultural High School, Setagaya-ku, Tokyo 158.

***) Tokyo University of Agriculture, Setagaya-ku, Tokyo 156. 


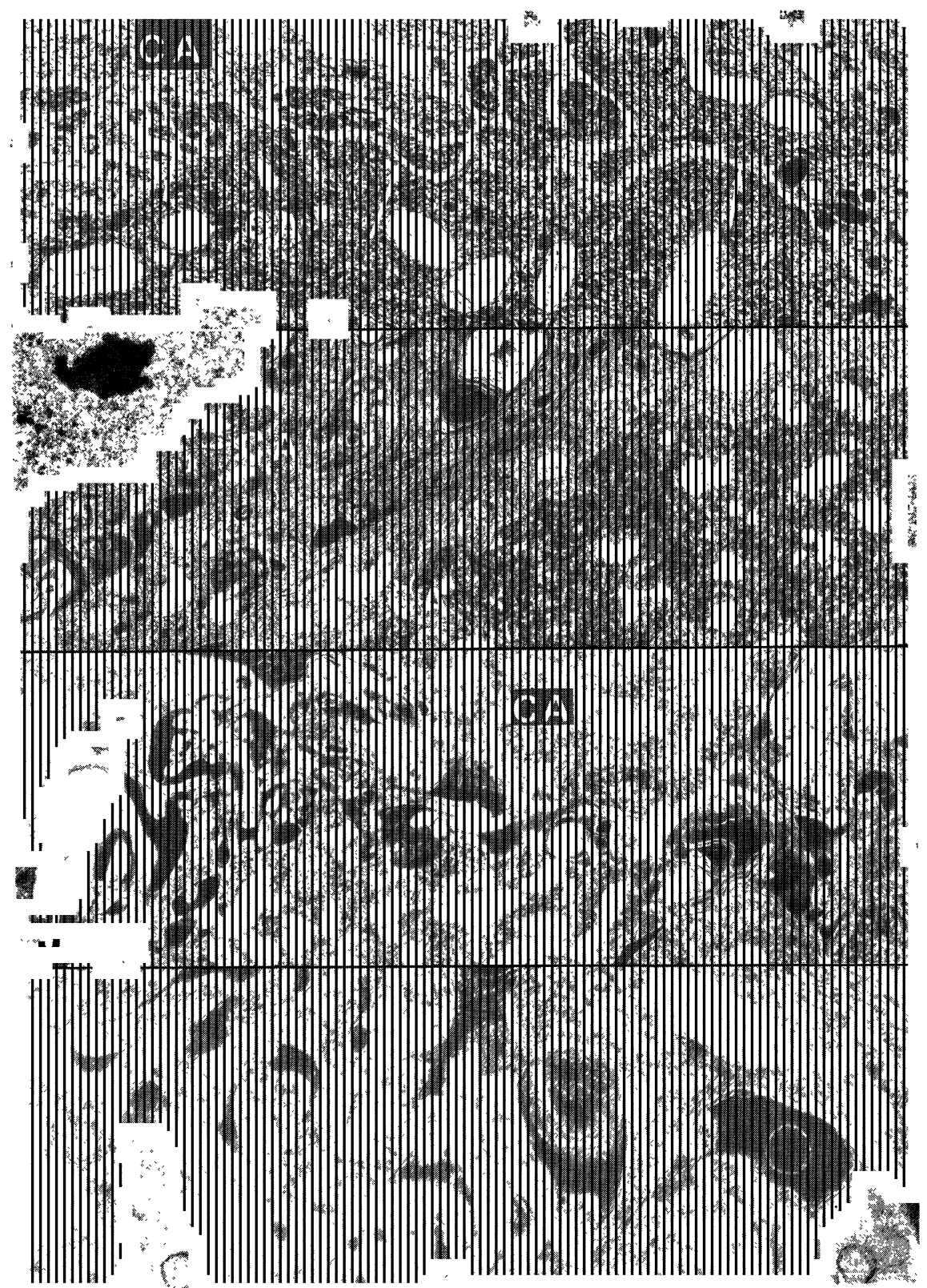

Fig. 1. CA of newly ecdysed 4th-instar-larvae (H-series). Arrows: Adjoining portions of CA cells. $\times 21,000$. Fig. 2. CA of newly ecdysed 5thinstar-larvae (H-series). $\times 10,000$. Fig. 3. CA of newly ecdysed 5thinstar-larvae (L-series). $\times 12,000$. Fig. 4. A high magnification electronmicrograph of a part of Fig. $3 . \times 30,000$. 

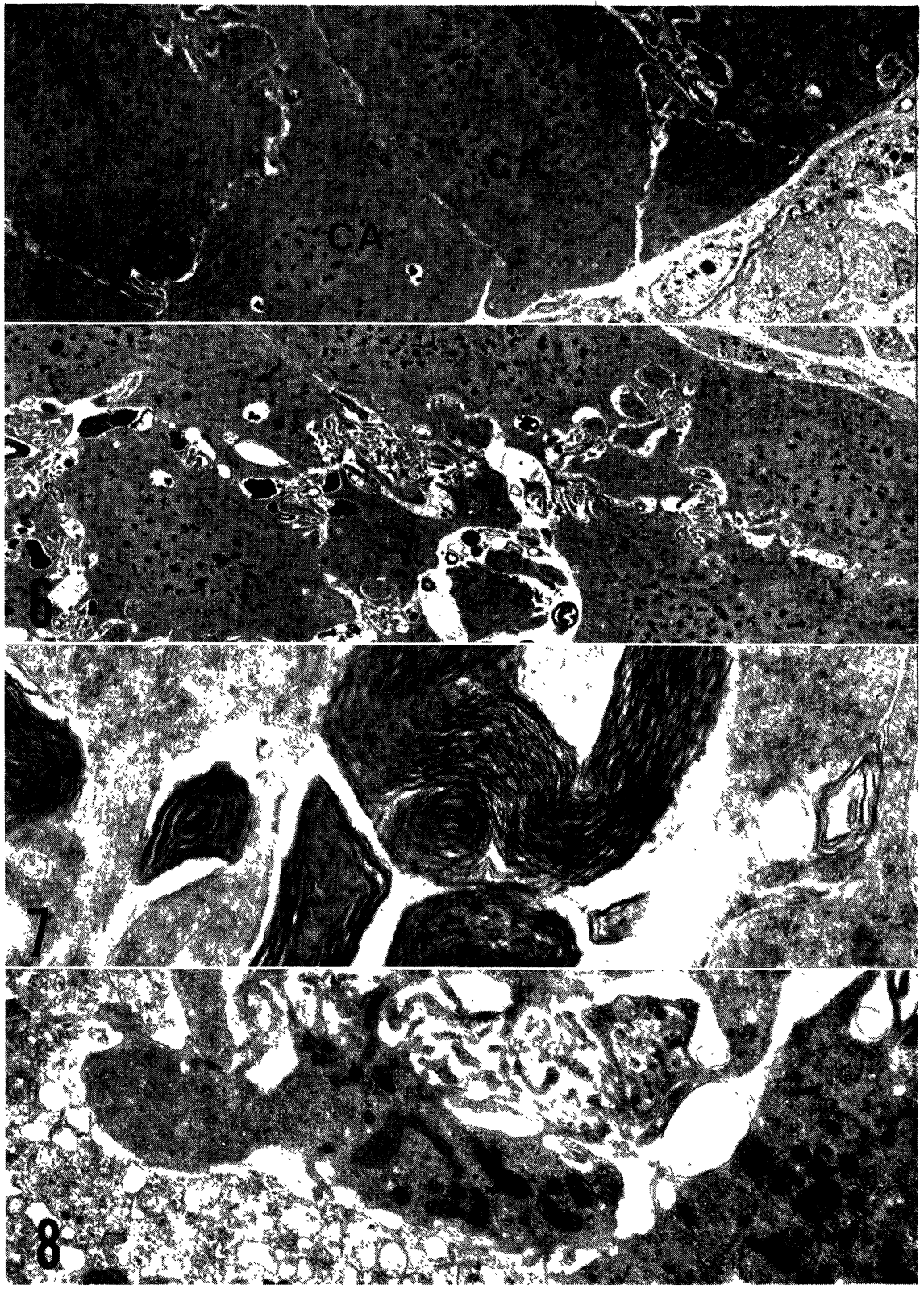

Fig. 5. CA of 4-day-old 5th-instar-larvae (H-series). $\times 3,000$. Fig. 6. CA of 4-day-old 5th-instar-larvae (L-series). $\times 3,000 . \quad$ Fig. 7. A high magnification electron-micrograph of a part of Fig. $6 . \times 22,500$. Fig. 8. CA of full grown larvae (L-series). $\times 6,000$. 

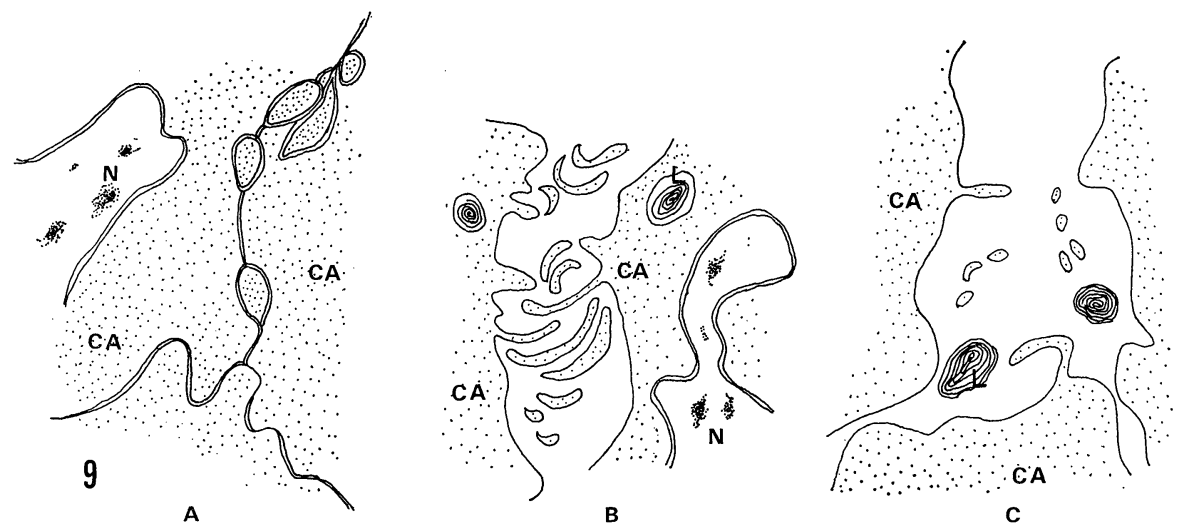

Fig. 9. Drawing of the ultrastructure of the CA. A: CA cells closely associated each other. B: Showing a loose CA junction. C: Loosely associated CA cells. N: Nucleus, L: Lysosome.

Fig. 5 shows the CA of the 4-day-old 5th-instar-larvae (H-series), and Fig. 6 indicates that of the 4-day-old 5th-instar-larvae (L-series) . The histolysis of cells was more remarkable in the L-series-larvae than in the H-series-larvae. Golgi apparatus and dense lysosomes were not apparent in the CA cytoplasm at this stage, though the dense lysosomes were still observed in the degenerating cells (Fig. 7). In the full grown larvae of the L-series, there were damage in some cells and survive in some others (Fig. 8).

Based on the above results, it seems that the CA activity corresponds to the histolysis of the CA cells, the disappearance of Golgi apparatus, and the occurrance of dense lysosomes. The electronmicroscopic observations demonstrated that the CA activity of the 5th-instar-larvae was weaker in the L-series than in the H-series in accordance with the results obtained experimentally and morphologically (XXII).

Acknowledgement. This investigation was supported by a grant in aid for Fundamental Scientific Research from the Ministry of Education, Japan.

\section{References}

Akai, H. (1971) : Exptl. Cell Res., 69, 219-223.

Morohoshi, S., Shimada, J., and Kagawa, T. (1974) : Proc. Japan Acad., XXII, 50, 161-166. 